\title{
Advances in endoscopic ultrasound, part 2: Therapy
}

\author{
Edward Kim MD ${ }^{1}$, Jennifer J Telford MD MPH FRCPC ${ }^{2}$
}

E ndoscopic ultrasound (EUS) is a relatively new endoscopic technique that provides high-resolution imaging by its unique ability to differentiate the histological layers of the gastrointestinal tract wall, as well as periluminal structures (1-4). Refinement of fine-needle aspiration (FNA) techniques has allowed for tissue and fluid sampling for diagnosis and staging, with the aid of newer techniques such as molecular analysis. EUS-FNA has led to the development of novel therapeutic methods, because therapeutic agents can now be delivered with EUS guidance into targeted areas by fine-needle injection (FNI). The advent of larger accessory channels and needles with a larger diameter has facilitated histopathological diagnosis of biopsy specimens, and enables the endosonographer to provide therapies such as tissue ablation and chemotherapy for the treatment of various neoplasms. The aim of the present article is to review some recent advances in the therapeutic role of EUS.

\section{INTRODUCTION}

Initially developed in the 1980s, EUS has seen increasing use in the past decade. First introduced as a diagnostic modality, it has enabled the endosonographer to visualize details of anatomy and pathology not previously attainable by most gastroenterologists or radiologists. The indications for EUS are expanding - forcing gastroenterologists to 'think outside the lumen' about possible therapeutic implications. The most common indications for EUS include diagnosis of solid and cystic lesions of the pancreas, subepithelial luminal pathology, biliary tract pathology and cancer staging. Established therapeutic indications include pseudocyst drainage and celiac plexus neurolysis (CPN) for pain from pancreatic adenocarcinoma. The advent of echoendoscopes with larger accessory channels, which can accommodate larger diameter devices, has led to experimentation in EUS-guided surgical therapy and natural orifice transgastric endoscopic surgery $(5,6)$.

The growing interest in EUS is best illustrated by the emerging therapeutic capabilities of this technology (Table 1). The introduction of linear echoendoscopes in the 1990s enabled the endosonographer to trace the path of the needle during FNA. FNA has allowed for diagnostic tissue and fluid sampling, but has also guided the development of newer therapeutic techniques. Pancreatic pseudocyst drainage is a common and well-known indication for EUS. However, an increasing number of case reports and case series have reported the successful use of EUS for the drainage of a variety of fluid collections accessible from the stomach, duodenum or rectum. These include hepatic, subphrenic and pelvic abscesses, bilomas, postoperative fluid collections, infected gallbladders and infected pancreatic necrotic collections. EUS is wellsuited for drainage of fluid collections and abscesses not easily amenable to computed tomography (CT) or ultrasound-guided percutaneous approaches due to intervening bowel, bladder and vascular structures (7-20).

In addition to aspirating tissue or fluid through an EUS-guided needle, substances may now be delivered with EUS guidance into targeted areas by FNI, most notably for CPN, which has been performed for more than a decade. EUS also permits precise targeting for the delivery of various substances directly into pancreatic, liver or subepithelial lesions. EUSFNI has been reported for the treatment of cystic and neuroendocrine neoplasms of the pancreas, gastrointestinal stromal tumours, hepatic metastases and esophageal cancer. EUS has become a useful tool in the localization of neuroendocrine tumours, but has also been used to perform fine-needle tattooing of pancreatic lesions to aid in their visualization and removal during surgery (21). In addition,

\section{TABLE 1}

Therapeutic indications for endoscopic ultrasound

\begin{tabular}{l}
\hline Established \\
\hline Celiac plexus neurolysis \\
Pancreatic pseudocyst drainage \\
Experimental \\
\hline Periluminal abscess drainage \\
Gastrointestinal bleeding \\
Cholangiopancreatography \\
Pancreatic cyst ablation \\
Cancer therapy \\
Chemotherapy \\
Radiation therapy \\
Radiofrequency ablation \\
Photodynamic therapy \\
Natural orifice transgastric endoscopic surgery
\end{tabular}

${ }^{1}$ Division of Internal Medicine, University of British Columbia; ${ }^{2}$ Division of Gastroenterology, St Paul's Hospital, Vancouver, British Columbia Correspondence: Dr Jennifer J Telford, University of British Columbia, Pacific Gastroenterology Associates, 770-1190 Hornby Street, Vancouver,

British Columbia V6Z 2K5. Telephone 604-688-6332 ext 224, fax 604-689-2004, e-mail jtelford@telus.net

Received and accepted for publication September 10, 2009 
EUS-FNI has been used for the treatment of subepithelial lesions, gastric varices, cholangiopancreatography after failed endoscopic retrograde cholangiopancreatography (ERCP) and to deliver novel radiation and chemo-based therapies in pancreatic cancer.

Part 1 of the present article reviewed recent advances in the diagnostic role of EUS (22). The aim of part 2 is to discuss innovations in EUS-FNI therapeutics.

\section{CELIAC PLEXUS NEUROLYSIS}

EUS-guided injection of anesthetic agents has been widely used for CPN to control abdominal pain in patients with pancreatic cancer and chronic pancreatitis. Multiple case reports and several prospective case series have documented the efficacy and safety of EUS-CPN for pain control in the setting of pancreatic cancer. However, pain relief with this technique in individuals with chronic pancreatitis has been disappointing, with only a minority of patients experiencing durable pain relief. More recently, EUS-guided neurolysis and nerve block has been performed for the treatment of chronic pelvic pain. A pilot study (23) reported the safety and feasibility of EUS-guided injection of anesthetic into the superior hypogastric plexus in patients with recalcitrant pelvic pain.

A recent meta-analysis evaluated the efficacy of EUSguided CPN for pain relief in patients with chronic pancreatitis and pancreatic cancer. With EUS-guided CPN, the pooled proportion of patients with pancreatic cancer who experienced pain relief was $80 \%$. In patients with pain due to chronic pancreatitis, EUS-guided CPN provided pain relief in $60 \%$. The authors concluded that EUS-guided CPN offers a safe alternative for pain relief in patients with chronic pancreatitis or pancreatic cancer. However, in patients with pain due to chronic pancreatitis, it was concluded that better techniques or novel injectable agents were needed to improve the response (24).

A report of 160 patients (25) compared the efficacy and safety of EUS-guided celiac plexus neurolysis/block (CPN/B) performed either by injecting at the base (central) or on either side (bilateral) of the celiac axis. The primary outcome was the per cent reduction in visual analogue pain scores at day 7 . Bilateral CPN/B was found to be more effective than central CPN/B (mean per cent pain reduction $70.4 \%$ versus $45.9 \%$; $\mathrm{P}=0.0016)$. The only complication reported involved self-limited bleeding due to laceration of the adrenal artery in an anticoagulated patient. The authors concluded that bilateral $\mathrm{CPN} / \mathrm{B}$ was more effective for pain relief than central CPN/B, and that bilateral CPN/B was a safe procedure, rarely leading to trauma to the left adrenal artery (25).

In a retrospective study by Levy et al (26), 33 patients with pancreatic cancer or chronic pancreatitis underwent EUS with identification and direct targeting of the celiac ganglia during EUS-CPN or CPB. It was hypothesized that more precise delivery of therapy could lead to improved safety and efficacy of the procedure. Twelve patients experienced pain during or immediately after the procedure, indicating initial neural destruction. Pain relief was reported more often in patients who developed this pain (92\%) compared with those who did not $(57 \%)$. Ninety-four per cent of the 17 patients with cancer reported pain relief but narcotic use decreased in only $18 \%$. Of the 18 patients with chronic pancreatitis, $80 \%$ who received alcohol injection reported pain relief compared with $38 \%$ who received steroid injection. No significant complications were reported in this study; however, three patients required hospitalization for management of pain after the procedure.

Wyse et al (27) recently presented an abstract detailing the first, randomized, double blind, sham-controlled trial of EUSguided CPN for pain due to inoperable pancreatic cancer. Patients with pancreatic cancer were eligible if they had tumour-related pain, cytological proof of adenocarcinoma and inoperable disease. Ninety-eight patients were randomly assigned to receive either bilateral EUS-CPN at the time of cytological diagnosis or conventional pain management. Although there was no effect on quality of life at three months, patients in the treatment group had significantly lower pain scores and reduced narcotic use in a subset who did not receive chemotherapy. No complications were reported, and the authors concluded that it may be reasonable to perform EUS-CPN in all patients with painful, inoperable, pancreatic cancer at the time of diagnosis by EUS.

EUS-CPN appears to be safe and effective in the management of pain secondary to pancreatic cancer; however, with the current injectables, is not appropriate for the routine treatment of pain due to chronic pancreatitis. Further studies are required to determine the optimal timing of $\mathrm{CPN}$ in patients with pancreatic cancer.

\section{GASTROINTESTINAL BLEEDING}

The use of EUS-guided therapy has been evaluated for refractory upper gastrointestinal bleeding, Dieulafoy lesions and varices. EUS imaging can provide additional detail of transmural structures, including the appearance, size and precise location of bleeding lesions and the anatomy of bleeding vessels. Localized therapy can then be used for lesions or vascular structures that are undetectable by standard endoscopic visualization.

Several case reports and series have reported the use of EUS to identify Dieulafoy's lesions associated with gastrointestinal bleeding. Treatment of submucosal vessels was performed using EUS visualization to apply hemoclips or sclerotherapy (28-30). Fockens et al (31) used EUS in eight patients with upper gastrointestinal bleeding and suspected Dieulafoy's lesions. In all eight patients, EUS was able to identify vessels penetrating the muscularis propria and the submucosa of the stomach, while standard gastroscopy was unable to visualize any abnormality. Among four patients undergoing sclerotherapy, three were performed under EUS guidance. During a median follow-up of 10 months, two patients experienced rebleeding, one from a duodenal ulcer during nonsteroidal anti-inflammatory drug use and the other from the gastric body, close to the scar from a previous sclerotherapy. The other six patients did not rebleed during the follow-up period.

EUS-FNI was evaluated by Levy et al (32) for the treatment of refractory upper gastrointestinal bleeding. Five patients, with an average of three previous episodes (range two to four) of severe bleeding requiring 18 (range 14 to 25) units of packed red blood cells and who had failed at least two attempts at hemostasis, underwent EUS-FNI. Under EUS guidance, 99\% alcohol was injected in two patients, one with a pancreatic pseudoaneurysm and the other with a duodenal Dieulafoy lesion. Of the remaining three patients, FNI using cyanoacrylate was 
used to treat two patients with a gastrointestinal stromal tumour and one patient with a duodenal ulcer. No recurrent bleeding or complications were reported. A subsequent case report by the same group (33) described successful hemostasis following EUS-guided microcoil injection into anastamotic varices after total pancreatectomy.

Several case reports and small case series have evaluated EUS-guided FNI for the treatment of actively bleeding gastric varices (34-36). Lee et al (34) treated 54 patients with gastric variceal bleeding with EUS-FNI of cyanoacrylate. Treatment was repeated until gastric varix obliteration was documented by EUS. A statistically significant reduction in the late rebleeding rate was found in this group compared with another group who received EUS-FNI of cyanoacrylate only with episodes of bleeding. Successful obliteration of varices was attained in $80 \%$ of patients in an average of just slightly more than two sessions. A series of five patients with bleeding gastric varices used EUSguided injection of cyanoacrylate, focusing on localization of the perforating veins as the target for injection. Hemostasis was achieved in all five patients. There were no cases of recurrent bleeding during a 10-month follow-up period and no complications were reported (37). EUS-FNI has also been studied in the prevention of esophageal variceal bleeding, using EUS to identify and target obliteration of the collateral vein to decrease varix recurrence. One controlled trial (38) randomly assigned 48 patients with esophageal varices to ethanolamine sclerotherapy using EUS guidance versus standard endoscopy. There was no significant difference in the number of sessions required for obliteration, time to successful obliteration or variceal recurrence rates.

Doppler ultrasound probes have been used to identify the culprit blood vessel in patients with peptic ulcer disease and gastric varices to provide prognostic information and to assist in therapy $(39,40)$. Several small studies have compared the presence of a positive signal using Doppler imaging with recognized endoscopic stigmata and found that the presence of an arterial signal correlated with high-risk stigmata and, therefore, risk of rebleeding. In addition, the absence of a signal was associated with a low risk of recurrent bleeding, even in those with high-risk stigmata. Furthermore, the presence of an arterial signal with Doppler was associated with recurrent bleeding in ulcers with a clean base $(41,42)$.

There is evolving evidence that in expert hands, EUS identification of blood vessels and guidance of FNI is useful for the treatment of refractory upper gastrointestinal bleeding from lesions difficult to evaluate with standard gastroscopy. Furthermore, EUS-FNI may be helpful in the management of gastric varices, although it does not appear to add to the current management of esophageal varices.

\section{EUS-GUIDED CHOLANGIOPANCREATOGRAPHY}

Endoscopic biliary drainage by ERCP may be unsuccessful due to tumour invasion of the duodenum, leading to duodenal obstruction, failed biliary cannulation, failure to traverse a biliary stricture or altered surgical anatomy. In these circumstances, percutaneous transhepatic biliary drainage or surgical intervention have traditionally been required, but may be associated with significant morbidity (43-45). Wiersema et al (46) first reported the use of EUS-guided injection of contrast through the duodenal wall into the common bile duct following unsuccessful ERCP. EUS enables the visualization of the left intrahepatic ducts, common bile duct and main pancreatic duct, and facilitates the puncture of a dilated biliary tract. Once access is achieved, cholangiography can be performed to assist in the placement of a guidewire and stent, without the need for an external drain. This can be accomplished directly or with a rendezvous technique, in which the guidewire is inserted in an anterograde fashion into the duodenum and used to guide ERCP stent placement (Figure 1). EUS-guided choledochoduodenostomy first appeared in the literature as case reports and small case series in patients with failed ERCP (47-50). In one such report published in 2001, Giovannini et al (47) documented the use of colour Doppler EUS in a patient with unsuccessful ERCP due to a mass at the head of the pancreas, with placement of a transduodenal stent performed under EUS guidance.

In a larger series, Kahaleh et al (51) reported on the use of EUS in 23 patients to access the biliary tract after failed ERCP attempts, leading to relief of obstruction in 21 of 23 (91\%) patients. Thirteen patients underwent transgastric puncture of a left intrahepatic duct, with placement of a guidewire across the papilla, followed by a rendezvous procedure in 11 of 13 cases. Complications over a 30-day period included one bile leak and two cases of self-limited pneumoperitoneum. Yamao et al (52) reported the long-term follow-up of five patients with malignant biliary obstruction who underwent successful stent placement using transudodenal EUS cholangioduodenostomy. One patient developed pneumoperitoneum that resolved with conservative management. Seven of eight (88\%) stent changes were successful, with one failed attempt due to tumour invasion. The average stent patency was longer than 200 days.

At least four case series have documented EUS techniques used to access and decompress the pancreatic duct in patients with chronic pancreatitis, using both transluminal and rendezvous approaches. All patients had unsuccessful ERCPs due to failed cannulation from severe inflammation, presence of a tight stricture or stone, or altered postsurgical anatomy. Except for one study, in which some patients had the pancreatic duct accessed through the duodenal bulb, all other transluminal approaches were through the stomach. Pain relief was experienced by $60 \%$ to $70 \%$ of patients, although the rate of response was not systematically evaluated. Stent migration and occlusion in $20 \%$ to $55 \%$ of cases with transluminal drainage was experienced in three of the four studies (53-56).

EUS-guided cholangiopancreatography, guidewire placement and stent insertion is an alternative to percutaneous methods in patients who fail ERCP. Adverse events include bile leak and guidewire fraying from contact with the needle. Although data are limited, the rendezvous technique with transpapillary stent placement is likely preferable to stent placement across the duodenal or gastric wall.

\section{CANCER THERAPY}

Pancreatic cancer is often diagnosed in later stages when curative resection is not possible. Therapeutic options have been limited to CPN for pain control and palliative chemoradiation therapy. Recent research has evaluated EUS-FNI of biological antitumour agents, cytotoxic and chemotherapeutic drugs, radioactive seeds and radioactive markers (fiducials) directly into pancreatic tumours to treat locally advanced disease. 

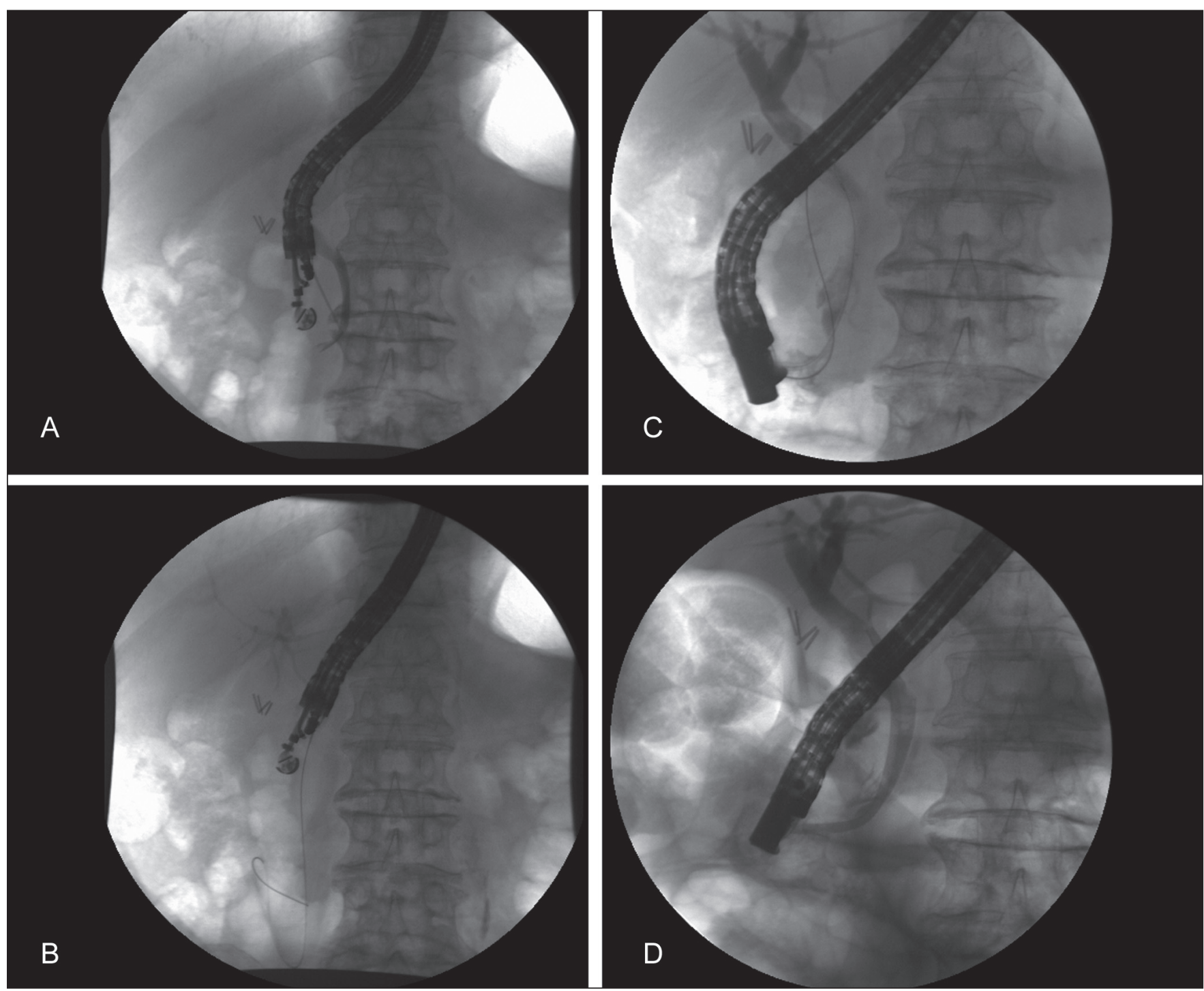

Figure 1) Endoscopic ultrasound (EUS)-guided cholangiography and guidewire placement in an 82-year-old woman with recurrent biliary pancreatitis and multiple unsuccessful endoscopic retrograde cholangiopancreatographies. Under EUS guidance, a 19 gauge needle was advanced into the common bile duct from the duodenum and a cholangiogram was obtained (A). The guidewire was advanced through the needle into the bile duct and across the papilla into the duodenum (B). The echoendoscope was then withdrawn and the duodenoscope and sphincterotome were backloaded onto the guidewire, resulting in successful retrograde cannulation of the biliary tree (C). A stent was placed to decrease the risk of a bile leak (D). Courtesy of Dr Eric Lam

Preliminary results suggest these techniques are safe and may be a useful adjunct or alternative to systemic chemotherapy, or radiation in pancreatic as well as other malignancies.

\section{Chemotherapeutic agents}

OncoGel: OncoGel (Bristol Myers-Squibb, USA) is a new formulation for intralesional injection of the chemotherapeutic drug paclitaxel, for local tumour management. OncoGel uses a thermosensitive, biodegradable drug delivery system, which, after injection and in response to body temperature, is transformed from a water-soluble polymer to a water-insoluble biodegradable hydrogel. This formulation releases paclitaxel continuously into the adjacent tissue for up to six weeks. A phase 1 study of OncoGel in superficially accessible, advanced solid cancer lesions has been completed in the United States and is currently undergoing phase 2 clinical studies for the treatment of incurable esophageal, lung and breast cancer.
Matthes et al (57) recently reported that EUS-guided injection of paclitaxel in the form of OncoGel led to therapeutic drug concentrations in the porcine pancreas. Other investigators have also used similar biodegradable polymers for sustained release with chemotherapeutic agents such as 5-fluorouracil and documented successful implantation into a canine pancreas under EUS-guidance (57-60).

TNFerade: TNFerade (GenVac Inc, USA) is a replicationdeficient adenoviral vector carrying the human tumour necrosis factor (TNF)-alpha gene regulated by Egr-1, a chemoradiation inducible promoter. With chemoradiation treatment, TNFalpha levels in the tumour increase, leading to tumour suppression (61). A multicentre study (62) reported the injection of TNFerade into locally advanced pancreatic cancer using EUS or percutaneous guidance. Among 37 patients who underwent this treatment, tumour stabilization was seen in $83 \%$ at one month and in $74 \%$ at three months. The authors concluded 
that there was some observed benefit in local control of the tumour as well as progression-free survival during a threemonth follow-up. The therapy was also generally well tolerated, and considered safe and effective.

Chang et al (63) recently published an abstract reporting a survival benefit of TNFerade in an interim analysis from an ongoing phase 3 pancreatic cancer clinical trial in patients with locally advanced pancreatic cancer. Of a total of 29 patients, nine received standard care, while 20 were treated with TNFerade by EUS $(n=17)$ or CT $(n=3)$ guidance in addition to standard of care. Kaplan-Meier survival analysis showed the overall mean survival was 14.7 months in the TNFerade group, and 11.1 months in the standard of care group $(\mathrm{P}=0.022)$.

\section{Immunotherapy}

Chang et al (64) evaluated the safety and feasibility of EUSFNI of a mixed lymphocyte culture of donor and host mononuclear cells (ie, cytoimplant) in patients with advanced pancreatic carcinoma. It was hypothesized that this procedure would stimulate tumour suppression through the activation of immune effector cells by the mixed lymphocyte reaction. Tumour response was assessed by CT or EUS in eight patients: two patients had a partial response (greater than 50\% decrease in tumour size), one had minimal response, three had no change and two had further progression of the tumour. Median survival was 13.2 months. No further studies using cytoimplants have been published.

\section{Radiation therapy}

Brachytherapy: Interstitial brachytherapy is used for the treatment of a number of solid organ tumours, most commonly prostate cancer. Radioactive seeds - iodine- 125 and palladium103 - are placed directly into tumour or lymph node tissue, producing localized tissue injury and tumour ablation through gamma radiation. An advantage of brachytherapy over traditional external beam radiation therapy is its ability to limit radiation toxicity to the normal tissues surrounding the cancer. EUS allows for the delivery of similar agents to lesions that are difficult to access percutaneously by CT or ultrasound guidance. Sun et al (65) first described the safe EUS-guided insertion of radioactive seeds in an animal model, with subsequent human experience limited to small case series, including head and neck cancer, recurrent esophageal cancer with perigastric adenopathy, pancreatic adenocarcinoma and lung cancer (66-68).

One series included 15 patients with unresectable pancreatic cancer who underwent EUS-guided implantation of radioactive seeds. During a median follow-up of 11 months, $27 \%$ of patients demonstrated a 'partial' tumour response, $20 \%$ showed a 'minimal' response and 33\% demonstrated 'stable disease'. Clinical benefit was shown in up to $30 \%$ of patients, mostly due to a reduction in pain. Procedure-related pancreatitis or pseudocyst formation was found in three patients, but these adverse events were considered mild and treated conservatively (65).

Stereotactic radiotherapy: Stereotactic radiotherapy uses a tracking system to focus multiple beams of precisely directed radiation using real-time image guidance. This tracking system follows the movements of the tumour through respiration and/or peristalsis with the use of fiducials that are implanted at the tumour site.

Fiducials can be surgically implanted or percutaneously placed with CT guidance. This can be technically difficult and there is a risk of tumour seeding with percutaneous access. EUS is ideally suited for placement of fiducial markers in both luminal and extraluminal gastrointestinal tumours, such as pancreatic cancer. Case series have demonstrated the feasibility of EUS-guided fiducial implantation in patients with tumours located in the mediastinum, retrocardiac region, retrocrural region, gastroesophageal junction, porta hepatis and pancreas (69-71). In one report (69), fiducials were placed under EUS-guidance in 13 patients with mediastinal or intraabdominal tumours, and then scheduled for CyberKnife (Accuray Inc, USA) stereotactic radiotherapy. The procedure was technically successful in 11 of 13 (84\%) patients, and in all seven patients undergoing placement for pancreatic cancer. This study did not evaluate the impact of this technique on patient survival or quality of life.

\section{PANCREATIC CYST ABLATION}

The recent refinements in EUS techniques have allowed gastoenterologists to more accurately identify pancreatic cystic neoplasms that may require surgery, or close surveillance with routine EUS-FNA and cyst fluid analysis. However, optimal management of cystic pancreatic neoplasms remains challenging. The traditional management of mucinous cystic neoplasms has been surgical resection, but a minimally invasive ablative procedure may offer elderly patients and high-risk surgical candidates an alternative to surgery.

As an alternative to surgery or routine monitoring, the role of EUS-guided ethanol ablation of pancreatic cystic neoplasms that do not communicate with the pancreatic duct has been suggested in pilot studies $(72,73)$. Ablative therapy of nonpancreatic cystic lesions has been reported for hepatic, renal and thyroid cysts, with encouraging results (74-77).

A pilot study of EUS-FNI for suspected mucinous cystic neoplasms by Gan et al (72) reported 25 patients with suspected mucinous cystic neoplasms based on EUS-FNA and cyst fluid analysis (Figure 2). The cysts were drained and then lavaged with various concentrations of ethanol, followed by complete evacuation of the cysts. In 23 patients with adequate follow-up, eight (35\%) had complete resolution of the cysts six to 12 months after the procedure. Of the remaining 15 patients, eight $(53 \%)$ had no reduction in size of their cysts, while two patients $(13 \%)$ displayed some reduction in size. Five patients ultimately underwent surgical resection and all had histological evidence of epithelial ablation. Four of 12 (33\%) patients who underwent ablation with 5\% to 40\% ethanol required surgical resection, compared with only one of $13(7.5 \%)$ patients who received $50 \%$ to $80 \%$ concentrations. However, this was not found to be statistically significant.

In another report (73), 14 patients with a variety of pancreatic cysts were treated with ethanol lavage combined with paclitaxel injection. These cysts included serous cystadenomas, lymphoepithelial cysts, pseudocysts and mucinous cysts. After a median follow-up of nine months, $79 \%$ of patients had complete resolution, with the development of mild pancreatitis in one patient. A randomized, double-blind trial by DeWitt et al (78) treated 42 patients with pancreatic cysts with ethanol or saline. Ethanol lavage $(n=25)$ resulted in a significantly greater decrease in cyst surface area $(-42.9 \%)$ compared with saline $(-11.4 \%$ [n=17]). After three months, 19 of $25(76 \%)$ and 14 of $17(82 \%)$ patients initially randomly assigned to ethanol and 


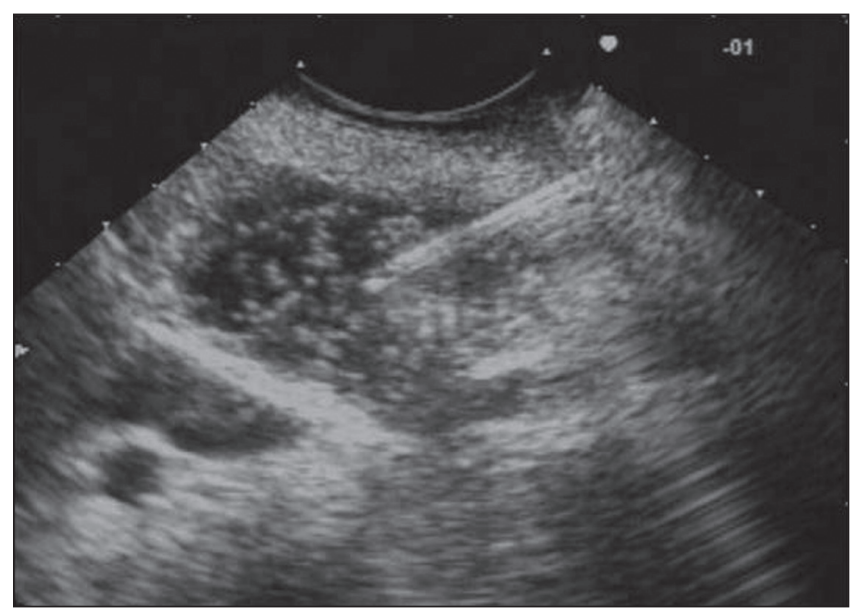

Figure 2) Endoscopic ultrasound-guided injection of ethanol into a pancreatic mucinous cystic lesion. Courtesy of Dr Ian Gan

saline solutions, respectively, were treated with open-label ethanol lavage. Imaging showed resolution of the pancreatic cysts in 12 of $36(33.3 \%)$ patients who underwent follow-up CT scans.

Although further study is needed, these preliminary data demonstrate the potential for EUS-FNI as a safe alternative to surgery for the treatment of pancreatic cystic neoplasms that do not communicate with the pancreatic duct.

\section{Alcohol ablation of solid tissue \\ Insulinomas are typically benign sporadic tumours that require complete resection to avoid recurrent symptoms of hypogly- cemia. Surgical resection is currently considered to be the standard treatment for symptomatic insulinomas. In the elderly and in patients at increased surgical risk, or those who refuse surgery, minimally invasive tumour ablation would be a desir- able alternative. Several case reports have described the suc- cessful ablation of symptomatic insulinomas with ethanol. The first reported EUS-guided ethanol ablation of an endocrine tumour was a $13 \mathrm{~mm}$ functioning insulinoma in a patient unfit for surgery. Ablation was performed by injecting $8 \mathrm{~mL}$ of $95 \%$ ethanol. The patient did not have any recurrence of hypogly- cemia, with no evidence of tumour recurrence observed on surveillance EUS at 34 months of follow-up $(79,80)$. \\ EUS-guided ethanol ablation for other gastrointestinal lesions has been described for hepatic metastases, gastrointes- tinal stromal tumours, as well as cystic and solid pancreatic lesions (81-85). Because ethanol solid tissue ablation in the pancreas and other gastrointestinal organs has been described only in case reports, routine use of these EUS-FNI techniques should be limited to research protocols and patients with lim- ited options.}

\section{Catheter-based solid tissue ablation}

Radiofrequency ablation (RFA) causes a predictable zone of coagulation necrosis by intense tissue heating, with relatively low morbidity compared with surgical intervention. RFA is usually performed by surgeons using an open or laparoscopic approach, or percutaneously by CT, MRI or ultrasound guidance, in patients with hepatocellular carcinoma or liver metastases. Accurate and precise targeting of the lesion is crucial to minimize the morbidity to the patient. EUS is ideally suited for RFA therapy of pancreatic lesions because it is often the best method of imaging and accessing the pancreas.

Goldberg et al (86) investigated the safety, feasibility and effectiveness of RFA under EUS guidance in an animal model. After RFA was applied in the tail of the pancreas, the area of necrosis was found to be approximately $8 \mathrm{~mm}$ to $12 \mathrm{~mm}$. One pig developed focal pancreatitis (less than $1 \mathrm{~cm}$ ), and three were found to have gastric burns, likely from improper electrode placement. The authors proposed that possible applications would include treatment of small functioning neuroendocrine tumours, poorly accessible liver lesions and palliation of unresectable pancreatic adenocarcinomas. More recently, a commercial cool-tipped device was designed and tested in an animal model for pancreatic ablation. Microwave and high frequency ultrasound have been used ablate tissue but are not currently available for EUS delivery (87).

Another emerging technique is photodynamic therapy (PDT), which uses a photosensitive agent that is selectively concentrated by the tumour and can be activated by light in the presence of oxygen. EUS-PDT involves EUS-guided placement of a light catheter into the target lesion using a large bore EUS needle. The light catheter exposes the tissue to laser light for $5 \mathrm{~min}$ to $15 \mathrm{~min}$, leading to activation of the photosensitive agent and subsequent photochemical tissue necrosis, with minimal damage to surrounding tissue. PDT has been used to treat adenocarcinomas of the esophagus and stomach, with some reports for the management of pancreatic cancer.

Bown et al (88) used PDT delivered percutaneously in 16 patients with inoperable pancreatic cancer. All showed evidence of substantial tumour necrosis on follow-up imaging, without evidence of pancreatitis. Two patients with gastroduodenal artery involvement had evidence of gastrointestinal bleeding, and three patients developed duodenal obstruction. The median survival was 9.5 months, with seven of 16 (44\%) alive after one year. Several groups studied the use of PDT for the ablation of normal tissue in animal models. Chan et al (89) documented localized tissue necrosis after PDT to liver, kidney, spleen and pancreas tissue, with no procedure-related complications or pancreatitis. There was no significant difference in the inflammation induced by PDT in the various organs. The authors concluded that EUS-guided low-dose PDT may be a safe and effective therapy for benign or malignant lesions. A recent study (90) documented a dose-response relationship with the amount of light exposure, with a maximum diameter of more than $3 \mathrm{~cm}$ after PDT of normal pancreatic tissue.

\section{CONCLUSION}

EUS is a minimally invasive imaging modality that can provide needle access to luminal and periluminal structures enabling both aspiration and injection. Established therapeutic indications are pancreatic pseudocyst drainage and CPN. Emerging uses include upper gastrointestinal hemostasis, cholangiopancreatography and stent placement, ablation of pancreatic cystic and solid neoplasms, and delivery of anticancer therapy in patients with inoperable pancreatic adenocarcinoma.

DISCLOSURE: Neither author reports any financial disclosures or conflicts of interest. 


\section{REFERENCES}

1. Tio TL, Tytgat GN. Endoscopic ultrasonography in analysing periintestinal lymph node abnormality. Preliminary results of studies in vitro and in vivo. Scand J Gastroenterol Suppl 1986;123:158-63.

2. Kimmey MB, Martin RW, Haggitt RC, et al. Histologic correlates of gastrointestinal ultrasound images. Gastroenterology 1989;96:433.

3. Wiersema MJ, Wiersema LM. High-resolution 25-megahertz ultrasonography of the gastrointestinal wall: Histologic correlates. Gastrointest Endosc 1993;39:499-504.

4. Tio TL, Tytgat GN. Endoscopic ultrasonography of normal and pathologic upper gastrointestinal wall structure. Comparison of studies in vivo and in vitro with histology. Scand J Gastroenterol 1986;123(Suppl):27-33.

5. Mintz Y, Talamini MA, Cullen J. Evolution of laparoscopic surgery: Lessons for NOTES. Gastrointest Endosc Clin N Am 2008; 18:225-34.

6. Fritscher-Ravens A. EUS-guided NOTES interventions. Gastrointest Endosc Clin N Am 2008;18:297-314.

7. Seewald S, Imazu H, Omar S, et al. EUS-guided drainage of hepatic abscess. Gastrointest Endosc 2005;61:495-8.

8. Seewald S, Brand B, Omar S, et al. EUS-guided drainage of subphrenic abscess. Gastrointest Endosc 2004:59:578-80.

9. Varadarajulu S, Drelichman ER. EUS-guided drainage of pelvic abscess (with video). Gastrointest Endosc 2007;66:372-6.

10. Giovannini M, Bories E, Moutardier V, et al. Drainage of deep pelvic abscesses using therapeutic echo endoscopy. Endoscopy 2003;35:511-4.

11. Shami VM, Talreja JP, Mahajan A, Phillips MS, Yeaton P, Kahaleh M. EUS-guided drainage of bilomas: A new alternative? Gastrointest Endosc 2008;67:136-40.

12. Ponnudurai R, George A, Sachithanandan S, et al. Endoscopic ultrasound-guided drainage of a biloma: A novel approach. Endoscopy 2006;38:199.

13. Subtil C, Moutardier V, Vitton V, et al. [Endoscopic management of postoperative pancreatic collections.] Gastroenterol Clin Biol 2008;32:128-33.

14. Lee DH, Cash BD, Womeldorph CM, Horwhat JD. Endoscopic therapy of a splenic abscess: Definitive treatment via EUS-guided transgastric drainage. Gastrointest Endosc 2006;64:631-4.

15. Benyoumes M, Deprez PH. A single therapeutic echo endoscope used for combined transgastric and transpapillary drainage of a pancreatic abscess. Endoscopy 2006;38:98

16. Imazu H, Kawahara Y, Koyama S, Tajiri H. Endoscopic ultrasoundguided transgastric drainage for omental bursa abscess complicating appendicitis with diffuse peritonitis. Endoscopy 2008;40(Suppl 2):E249.

17. Kwan V, Eisendrath P, Antaki F, Le Moine O, Deviere J. EUSguided cholecystenterostomy: A new technique (with videos). Gastrointest Endosc 2007;66:582-6.

18. Lee SS, Park do H, Hwang CY, et al. EUS-guided transmural cholecystostomy as rescue management for acute cholecystitis in elderly or high-risk patients: A prospective feasibility study. Gastrointest Endosc 2007;66:1008-12.

19. Ciesek S, Manns MP, Krüger M. [Retroperitoneal abscess in a man with severe necrotizing pancreatitis.] Dtsch Med Wochenschr 2006;131:1937-40.

20. Jah A, Jamieson N, Huguet E, Griffiths W, Carroll N, Praseedom R. Endoscopic ultrasound-guided drainage of an abdominal fluid collection following Whipple's resection. World J Gastroenterol 2008;14:6867-8.

21. Gress FG, Barawi M, Kim D, et al. Preoperative localization of a neuroendocrine tumor of the pancreas with EUS-guided fine needle tattooing. Gastrointest Endosc 2002;55:594-7.

22. Kim E, Telford JJ. Endoscopic ultrasound advances, part 1: Diagnosis. Can J Gastroenterol 2009;23:594-601.

23. Ayub K. Endoscopic ultrasound-guided superior hypogastric plexus neurolysis: A new technique for the management of pelvic pain. Gastrointest Endosc 2002;56:S143.

24. Puli SR, Reddy JB, Bechtold ML, Antillon MR, Brugge WR. EUS-guided celiac plexus neurolysis for pain due to chronic pancreatitis or pancreatic cancer pain: A meta-analysis and systematic review. Dig Dis Sci 2009 [Epub ahead of print].

25. Sahai AV, Lemelin V, Lam E, Paquin SC. Central vs. bilateral endoscopic ultrasound-guided celiac plexus block or neurolysis: A comparative study of short-term effectiveness. Am J Gastroenterol 2009;104:326-9.
26. Levy MJ, Topazian MD, Wiersema MJ, et al. Initial evaluation of the efficacy and safety of endoscopic ultrasound-guided direct ganglia neurolysis and block. Am J Gastroenterol 2008;103:98-103.

27. Wyse JM, Carone M, Usatii M, Paquin SC, Sahai A. Results of the first, randomized, double blind, sham-controlled trial of EUS-guided celiac plexus neurolysis (EUS-CPN) for pain due to newly diagnosed, inoperable pancreatic cancer. Gastrointest Endosc 2009;69:AB132. (Abst)

28. Ribeiro A, Vazquez-Sequeiros E, Wiersema MJ. Doppler EUS-guided treatment of gastric Dieulafoy's lesion. Gastrointest Endosc 2001;53:807-9.

29. Folvik G, Nesje LB, Berstad A, Odegaard S. Endosonographyguided endoscopic band ligation of Dieulafoy's malformation: A case report. Endoscopy 2001;33:636-8.

30. Raju GS, Faruqi S, Bhutani MS, Soloway R. Catheter probe EUSassisted treatment with hemoclips of a colonic Dieulafoy's lesion with recurrent bleeding. Gastrointest Endosc 2004;60:851-4.

31. Fockens P, Meenan J, van Dullemen HM, Bolwerk CJ, Tytgat GN. Dieulafoy's disease: Endosonographic detection and endosonography-guided treatment. Gastrointest Endosc 1996;44:437-42.

32. Levy MJ, Wong Kee Song LM, Farnell MB, Misra S, Sarr MG, Gostout CJ. Endoscopic ultrasound (EUS)-guided angiotherapy of refractory gastrointestinal bleeding. Am J Gastroenterol 2007;103:352-9.

33. Levy MJ, Wong Kee Song LM, Kendrick ML, Misra S, Gostout CJ. EUS-guided coil embolization for refractory ectopic variceal bleeding (with videos). Gastrointest Endosc 2008;67:572-4.

34. Lee YT, Chan FK, Ng EK, et al. EUS-guided injection of cyanoacrylate for bleeding gastric varices. Gastrointest Endosc 2000;52:168-74 Comment in: Gastrointest Endosc 2000;52:298-301.

35. Battaglia G, Bocus P, Morbin T, Ancona E. Endoscopic Doppler US-guided injection therapy for gastric varices: Case report. Gastrointest Endosc 2003;57:608-11.

36. Matsumoto A, Takimoto K, Yamauchi Y, Kuchide M, Takemura T. Limitations of cyanoacrylate injection in the treatment of gastric fundal varices. Endoscopy 2004;36:925; author reply 925-6 Comment on: Endoscopy 2004;36:239-41.

37. Romero-Castro R, Pellicer-Bautista FJ, Jimenez-Saenz M, et al. EUS-guided injection of cyanoacrylate in perforating feeding veins in gastric varices: Results in 5 cases. Gastrointest Endosc 2007;66:402-7.

38. de Paulo GA, Ardengh JC, Nakao FS, Ferrari AP. Treatment of esophageal varices: A randomized controlled trial comparing endoscopic sclerotherapy and EUS-guided sclerotherapy of esophageal collateral veins. Gastrointest Endosc 2006;63:396-402.

39. Wong RC, Farooq FT, Chak A. Endoscopic Doppler US probe for the diagnosis of gastric varices (with videos). Gastrointest Endosc 2007;65:491-6.

40. Wong RC. Endoscopic Doppler US probe for acute peptic ulcer hemorrhage. Gastrointest Endosc 2004;60:804-12.

41. Kohler B, Riemann JF. Endoscopic injection therapy of Forrest 2 and 3 gastroduodenal ulcers guided by endoscopic ultrasound. Endoscopy 1993;25:219-23.

42. Chen VK, Wong RC. Endoscopic Doppler ultrasound versus endoscopic stigmata-directed management of acute peptic ulcer hemorrhage: A multimodel cost analysis. Dig Dis Sci 2007;52:161.

43. Smith AC, Dowset JF, Russel RC, et al. Randomised trial of endoscopic stenting versus surgical bypass in malignant low bile duct obstruction. Lancet 1994;344:1655-60.

44. Lai EC, Mok FP, Tan ES, et al. Endoscopic biliary drainage for severe acute cholangitis. N Engl J Med 1992;24:1582-6.

45. Winnick AB, Waybill PN, Venbrux AC. Complications of percutaneous transhepatic biliary interventions. Tech Vasc Interv Radiol 2001;4:200-6.

46. Wiersema MJ, Sandusky D, Carr R, Wiersema LM, Erdel WC, Frederick PK. Endosonography-guided cholangiopancreatography. Gastrointest Endosc 1996;43(2Pt1):102-6.

47. Giovannini H, Moutardier B, Pesenti C, et al. Endoscopic ultrasound-guided bilioduodenal anastamoses: A new technique for biliary drainage. Endoscopy 2001;33:898-900.

48. Burmester E, Niehaus J, Leineweber T, et al. EUS-cholangiodrainage of the bile duct: Report of four cases. Gastrointest Endosc 2003;57:246-51. 
49. Yamao K, Sawaki A, Takahashi K, et al. EUS-guided choledochoduodenostomy for palliative biliary drainage in case of papillary obstruction: Report of two cases. Gastrointest Endosc 2006;64:663-7.

50. Ang TL, Teo EK, Fock KM. EUS-guided transduodenal biliary drainage in unresectable pancreatic cancer with obstructive jaundice. JOP;8:438-43.

51. Kahaleh M, Hernandez AJ, Tokar J, et al. Interventional EUSguided cholangiography: Evaluation of a technique in evolution. Gastrointest Endosc 2006;64:52-9.

52. Yamao K, Bhatia V, Mizuno N, et al. EUS-guided choledochoduodenostomy for palliative biliary drainage in patients with malignant biliary obstruction: Results of long-term follow-up. Endoscopy 2008;40:340-2.

53. Tessier G, Bories E, Arvanitakis M, et al. EUS-guided pancreatogastrostomy and pancreatobulbostomy for the treatment of pain in patients with pancreatic ductal dilation inaccessible for transpapillary endoscopic therapy. Gastrointest Endosc 2007;65:233-41.

54. Kahaleh M, Hernandez AJ, Tokar J, et al. EUS-guided pancreaticogastrostomy: Analysis of its efficacy to drain inaccessible pancreatic ducts. Gastrointest Endosc 2007;65:224-30.

55. Will U, Fueldner F, Thieme AK, et al. Transgastric pancreatography and EUS-guided drainage of the pancreatic duct. J Hepatobiliary Pancreat Surg 2007;14:377-82.

56. Mallery S, Matlock J, Freeman ML. EUS-guided rendezvous drainage of obstructed biliary and pancreatic ducts: Report of 6 cases. Gastrointest Endosc 2004;59:100-7.

57. Matthes K, Mino-Kenudson M, Sahani DV, et al. EUS-guided injection of paclitaxel (OncoGel) provides therapeutic drug concentrations in the porcine pancreas (with video). Gastrointest Endosc 2007;65:448-53 Comment in: Gastrointest Endosc 2007;65:454-6.

58. Zentner GM, Rathi R, Shih C, et al. Biodegradable block copolymers for delivery of proteins and water-insoluble drugs. J Control Release 2001;72:203-15.

59. Vukelja SJ, Anthony SP, Arseneau JC, et al. Phase 1 study of escalating-dose OncoGel (ReGel/paclitaxel) depot injection, a controlled-release formulation of paclitaxel, for local management of superficial solid tumor lesions. Anticancer Drugs 2007;18:283-9.

60. Sun S, Wang S, Ge N, et al. Endoscopic ultrasound-guided interstitial chemotherapy in the pancreas: Results in a canine model. Endoscopy 2007;39:530-4.

61. Senzer N, Mani S, Rosemurgy A, et al. TNFerade biologic, an adenovector with a radiation-inducible promoter, carrying the human tumor necrosis factor alpha gene: A phase I study in patients with solid tumors. J Clin Oncol 2004;22:592-601.

62. Chang KJ, Senzer N, Chung T, et al. A novel gene transfer therapy against pancreatic cancer (TNFerade) delivered by endoscopic ultrasound (EUS) and percutaneous guided fine needle injection (FNI). Gastrointestinal Endoscopy 2004;59:Ab92. (Abst)

63. Chang KJ, Ashida R, Muthusamy R, et al. Overall survival in locally advanced pancreatic cancer patients treated with a biologic using endoscopic ultrasound (EUS) FNI or CT-guided injection: A single institution experience. Gastrointest Endosc 2009;69:AB132-3. (Abst)

64. Chang KJ, Nguyen PT, Thompson JA, et al. Phase I clinical trial of allogeneic mixed lymphocyte culture (cytoimplant) delivered by endoscopic ultrasound-guided fine-needle injection in patients with advanced pancreatic carcinoma. Cancer 2000;88:1325-35.

65. Sun S, Xu H, Xin J, Liu J, Guo Q, Li S. Endoscopic ultrasoundguided interstitial brachytherapy of unresectable pancreatic cancer: Results of a pilot trial. Endoscopy 2006;38:399-403.

66. Lah JJ, Kuo JV, Chang KJ, Nguyen PT. US-guided brachytherapy. Gastrointest Endosc 2005;62:805-8.

67. Maier W, Henne K, Krebs A, Schipper J. Endoscopic ultrasoundguided brachytherapy of head and neck tumours. A new procedure for controlled application. J Laryngol Otol 1999;113:41-8.

68. Jin Z, Du Y, Li Z, Jiang Y, Chen J, Liu Y. Endoscopic ultrasonography-guided interstitial implantation of iodine- 125 seeds combined with chemotherapy in the treatment of unresectable pancreatic carcinoma: A prospective pilot study. Endoscopy 2008;40:314-20.
69. Pishvaian AC, Collins B, Gagnon G, Ahlawat S, Haddad NG. EUS-guided fiducial placement for CyberKnife radiotherapy of mediastinal and abdominal malignancies. Gastrointest Endosc 2006;64:412-7.

70. Ellsmere JC, Mahadevan A, Kelleher T, et al. EUS-guided radiotherapy fiducials for upper gastrointestinal malignancies. Gastrointest Endosc 2007;65:Ab208. (Abst)

71. Savides TJ. EUS-guided fine-needle insertion of radiopaque fiducials: X marks the spot. Gastrointest Endosc 2006;64:412-7.

72. Gan SI, Thompson CC, Lauwers GY, Bounds BC, Brugge WR. Ethanol lavage of pancreatic cystic lesions: Initial pilot study. Gastrointest Endosc 2005;61:746-52.

73. Oh HC, Seo DW, Lee TY, et al. New treatment for cystic tumors of the pancreas: EUS-guided ethanol lavage with paclitaxel injection. Gastrointest Endosc 2008;67:636-42.

74. Okano A, Hajiro K, Takakuwa H, et al. Alcohol sclerotherapy of hepatic cysts: Its effect in relation to ethanol concentration. Hepatol Res 2000;17:179-84.

75. Blonski WC, Campbell MS, Faust T, et al. Successful aspiration and ethanol sclerosis of a large, symptomatic simple liver cyst: Case presentation and review of the literature. World J Gastroenterol 2006;12:2949-54.

76. Agostini S, Dedola GL, Gabbrielli S. Percutaneous treatment of simple renal cysts with sclerotherapy and extended drainage. Radiol Med (Torino) 2004;108:522-9.

77. Verde G, Papini E, Pacella CM, et al. Ultrasound guided percutaneous ethanol injection in the treatment of cystic thyroid nodules. Clin Endocrinol (Oxf) 1994;41:719-24.

78. DeWitt J, McGreevy K, Schmidt CM, et al. Ethanol pancreatic injection of cysts (EPIC): Preliminary results of a prospective multicenter, randomized, double blinded study. Gastrointest Endosc 2007;65:AB106. (Abst)

79. Jurgensen C, Schuppan D, Neser F, Ernstberger J, Junghans U, Stolzel U. EUS-guided alcohol ablation of an insulinoma. Gastrointest Endosc 2006;63:1059-62.

80. Deprez PH, Claessens A, Borbath I, Gigot JF, Maiter D. Successful endoscopic ultrasound-guided ethanol ablation of a sporadic insulinoma. Acta Gastroenterol Belg 2008;71:333-7.

81. Barclay RL, Perez-Miranda M, Giovannini M. EUS-guided treatment of a solid hepatic metastasis. Gastrointest Endosc 2002;55:266-70.

82. Matthes K, Mino-Kenudson M, Sahani DV, Holalkere N, Brugge WR. Concentration-dependent ablation of pancreatic tissue by EUS-guided ethanol injection. Gastrointest Endosc 2007;65:272-7. Comment in: Gastrointest Endosc 2007;65:278-80.

83. Matsumoto K, Yamao K, Okubo K, et al. Endoscopic ultrasoundguided ethanol injection in the pancreas in a porcine model: A preliminary study. J Gastroenterol Hepatol 2008;23(7 Pt 2):e1-6.

84. Aslanian H, Salem RR, Marginean C, Robert M, Lee JH, Topazian M. EUS-guided ethanol injection of normal porcine pancreas: A pilot study. Gastrointest Endosc 2005;62:723-7.

85. Gunter E, Lingenfelser T, Eitelbach F, Muller H, Ell C. EUS-guided ethanol injection for treatment of a GI stromal tumor. Gastrointest Endosc 2003;57:113-5.

86. Goldberg SN, Mallery S, Gazelle GS, Brugge WR. EUS-guided radiofrequency ablation in the pancreas: Results in a porcine model. Gastrointest Endosc 1999;50:392-401.

87. Carrara S, Arcidiacono PG, Albarello L, et al. Endoscopic ultrasound-guided application of a new hybrid cryotherm probe in porcine pancreas: A preliminary study. Endoscopy 2008;40:321-6.

88. Bown SG, Rogowska AZ, Whitelaw DE, et al. Photodynamic therapy for cancer of the pancreas. Gut 2002;50:549-57.

89. Chan HH, Nishioka NS, Mino M, et al. EUS-guided photodynamic therapy of the pancreas: A pilot study. Gastrointest Endosc 2004;59:95-9.

90. Yusuf TE, Matthes K, Brugge WR. EUS-guided photodynamic therapy with verteporfin for ablation of normal pancreatic tissue: A pilot study in a porcine model (with video). Gastrointest Endosc 2008;67:957-61. Comment in: Gastrointest Endosc 2008;67:961-3. 


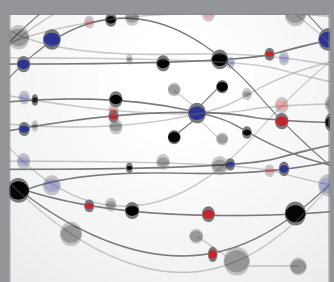

The Scientific World Journal
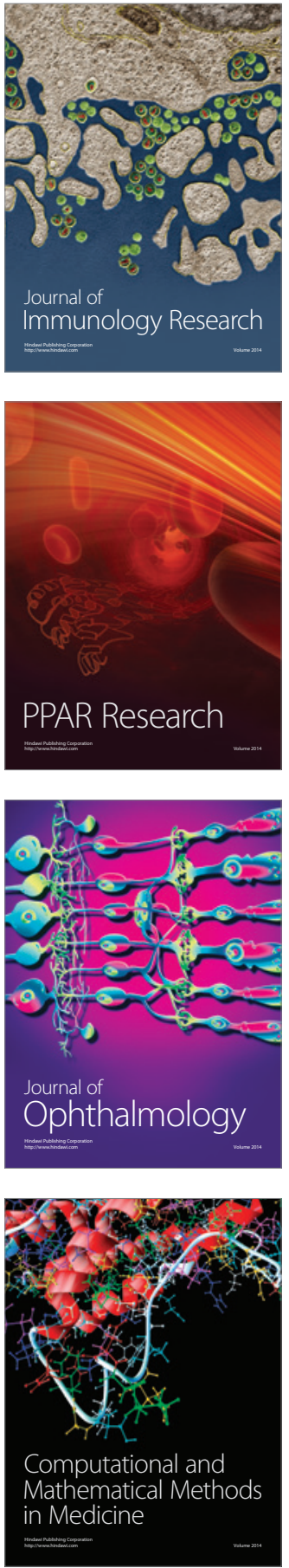

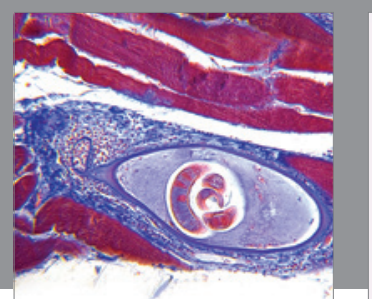

Gastroenterology Research and Practice

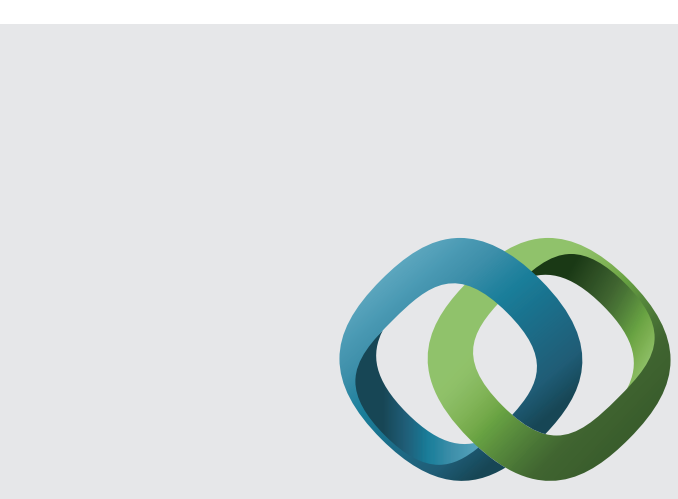

\section{Hindawi}

Submit your manuscripts at

http://www.hindawi.com
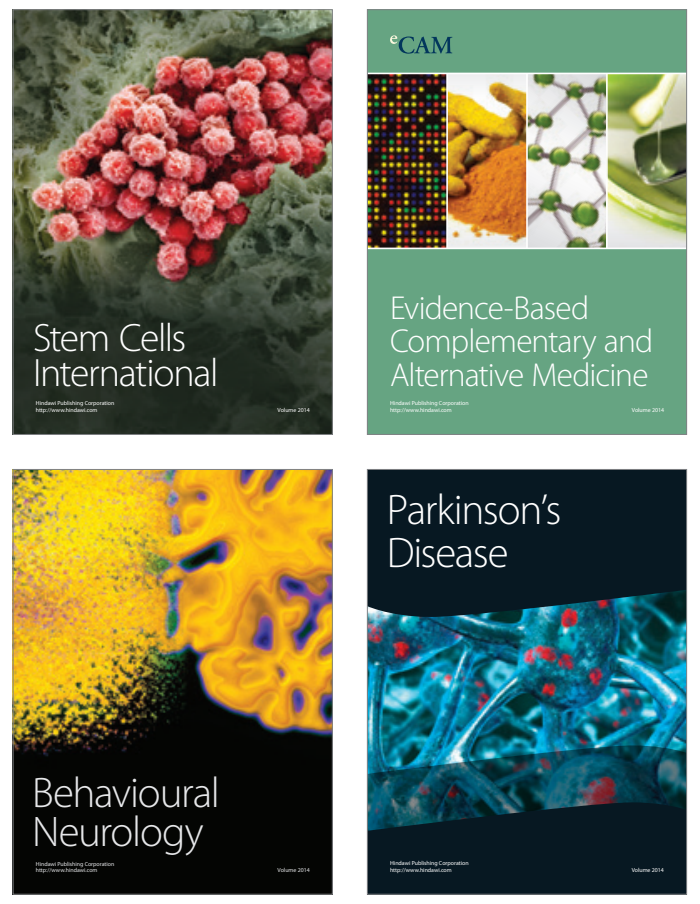
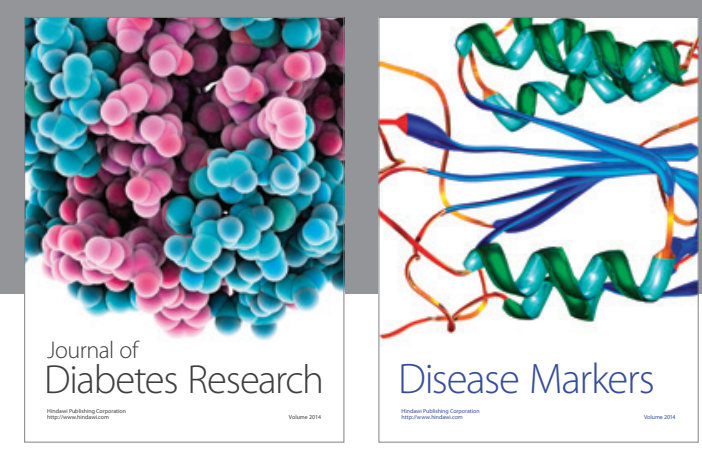

Disease Markers
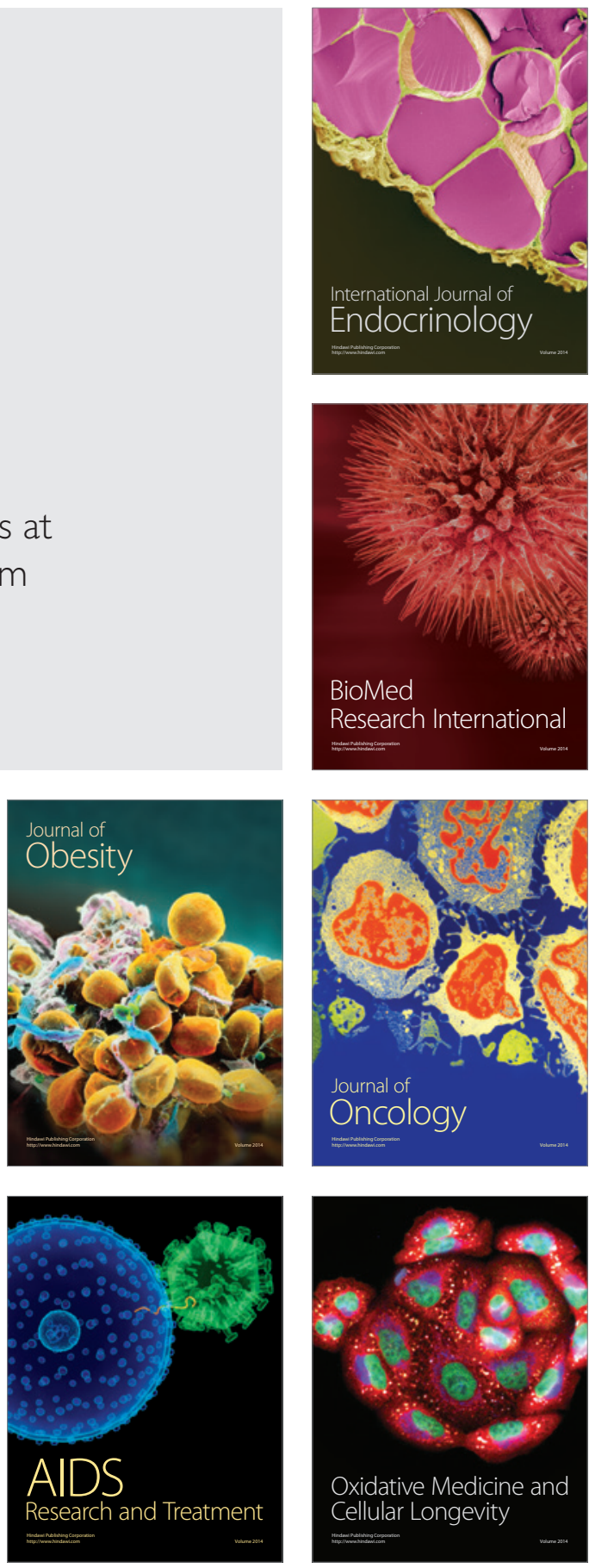